\title{
LEITURA LITERÁRIA NA FORMAÇÃO HUMANA: POESIA NO ENSINO MÉDIO
}

\author{
LITERARY COURSE IN THE HUMAN FORMATION: \\ POETRY IN THE SECONDARY EDUCATION \\ LECTURA LITERARIA EN LA FORMACIÓN HUMANA: \\ POESÍA EN LA ENSEÑANZA MEDIA
}

\author{
Rosana Andres Dalenogare ${ }^{1}$ \\ Flávia BRocchetto Ramos ${ }^{2}$ \\ José EDIMAR DE SOUZA ${ }^{3}$
}

Universidade de Caxias do Sul (UCS). Caxias do Sul/RS-Brasil ${ }^{1}$

Universidade de Caxias do Sul (UCS). Caxias do Sul/RS-Brasil ${ }^{2}$

Universidade de Caxias do Sul (UCS). Caxias do Sul/RS-Brasil ${ }^{3}$

Resumo O Ensino Médio é um período de descobertas e decisões para o adolescente, e nós, professores, sabemos que a leitura literária pode contribuir substancialmente para a formação humana nesse momento. Por isso, este artigo tem como objetivo analisar a poesia Sobre estas duras, cavernosas fragas, do autor Bocage, a fim de identificar aspectos que possam contribuir para a emancipação do aluno, a partir da mobilização dos recursos históricos, estruturais e temáticos. Elaboramos breve histórico do ensino da Literatura no Brasil e analisamos a poesia. Constatamos que a escolha do vocabulário, a relação de sentimentos com elementos da natureza, aliados à temática do conflito entre razão e emoção, podem ser relacionados com a vida do leitor, bem como, contribuir para a compreensão e para a reflexão sobre a realidade. Dessa forma, a mediação da leitura de poesias pode colaborar para a formação do aluno de Ensino Médio por meio da reflexão, conhecimento e compreensão de si, do outro e do mundo.

Palavras-chave: Leitura; Poesia; Ensino Médio.

Abstract Secondary Education constitutes a period of discoveries and decisions for teenagers and, we, teachers, know that literary reading can contribute substantially to human formation at that time. Therefore, this article aims tat analyzing the poem Sobre estas duras, 
cavernosas fragas, by Bocage, in order to identify aspects that may contribute to the emancipation of the student, from the mobilization of historical, structural and thematic resources. We elaborated a brief history of the teaching of Literature in Brazil and analyzed poetry. We note that the choice of vocabulary, the relationship of feelings with elements of nature, allied to the theme of the conflict between reason and emotion, can be related to the reader's life, as well as contributing to understanding and reflecting on reality. In this way, the mediation of poetry reading can collaborate for the formation of the student of Secondary Education through reflection, knowledge and understanding of oneself, the other and the world. Keywords: Reading: Poetry; Secondary education.

Resumen La Enseñanza Media es un periodo de descubrimientos y decisiones para el adolescente y, nosotros, profesores, sabemos que la lectura literaria puede contribuir sustancialmente para la formación humana en ese momento. Por eso, este artículo tiene por objetivo analizar el poema Sobre estas duras, cavernosas fragas, del autor Bocage, a fin de identificar aspectos que puedan contribuir para la emancipación del alumno, a partir de la movilización de los recursos históricos, estructurales y temáticos. Elaboramos breve histórico de la enseñanza de la Literatura en Brasil y analizamos la poesía. Constatamos que la elección del vocabulario, la relación de sentimientos con elementos de la naturaleza, aliados a la temática del conflicto entre razón y emoción, pueden ser relacionados con la vida del lector, así como contribuir para la comprensión y para la reflexión sobre la realidad. De esa forma, la mediación de la lectura de poesías puede colaborar para la formación del alumno de Enseñanza Media a través de la reflexión, conocimiento y comprensión de sí, del otro y del mundo.

Palabras clave: Lectura; Poesía; Enseñanza Media.

\section{INTRODUÇÃo}

Durante o Ensino Médio, o estudante vive momentos decisivos, pois essa fase da escolarização implica tomada de decisões para a vida adulta. Dentre essas decisões, está a participação em sociedade como cidadão e a entrada no mercado de trabalho. Ambas exigem posicionamento crítico, além de conhecimento sobre si, do outro e do mundo. Frente a esse cenário, a leitura literária pode auxiliar na formação do aluno, ao possibilitar a reflexão e o conhecimento.

Pela vivência em escolas, percebemos que muitos alunos durante o Ensino Médio não têm o costume de ler e têm dificuldade para escrever e interpretar textos. Quando se trata da leitura literária, o problema é ainda maior, pois a maioria dos estudantes não lê e, quando o faz, é por obrigação, em geral, na disciplina de Literatura. Segundo Lajolo (2000), esse fato pode estar ligado à forma como a Literatura é trabalhada nas escolas, não somente no Ensino Médio, mas em toda a Educação Básica.

Independente do lugar que a literatura ocupa na escolarização, entendemos que a leitura literária teria papel de destaque desde o início da formação escolar, uma vez que con- 
tribui para a humanização do indivíduo (CANDIDO, 2011). Candido (2011) alerta que o acesso à literatura seria um direito humano, uma vez que nos é intrínseca a possibilidade $\mathrm{e}$ a necessidade de fabulação.

Nessa mesma linha de pensamento, trazemos Freire (1987) que compreende a humanização e a desumanização como possibilidades na história do homem. Entretanto, somente a primeira é vocação histórica dos seres humanos, que inclui a luta por justiça e libertação de movimentos opressores, pelo trabalho livre, pela desalienação, pela afirmação dos homens como pessoas.

Humanização, neste estudo, é entendida como um processo de busca permanente, uma vez que somos seres conscientes de nossa inconclusão e buscamos "ser mais", ou seja, procuramos nosso aprimoramento nas variadas áreas durante nossa existência. Quando essa vocação humana é negada, ocorre a desumanização, de forma que o ser humano se torna oprimido por quem tem mais poder e passa a aceitar imposições sociais sem refletir e questionar.

A educação para a autonomia, defendida por Freire (2010), valoriza a reflexão crítica, o respeito, a ética, o diálogo e o reconhecimento do educador e do educando como seres em construção. Textualmente, afirma: "Ninguém é sujeito da autonomia de ninguém" (FREIRE 2010, p. 107) e acrescenta: "A gente vai amadurecendo todo dia, ou não. A autonomia, enquanto amadurecimento do ser para si, é processo, é vir a ser. Não ocorre em data marcada" (FREIRE 2010, p. 107).

Assim como a educação, a autonomia é um processo contínuo; é por meio da tomada de decisões nas diversas situações cotidianas que a construímos. Esse amadurecimento leva o ser à sua emancipação por meio da reflexão e do respeito ao outro. É com essa autossuficiência que a liberdade toma lugar da dependência e nos tornamos responsáveis pelo que somos. É próprio desse ideal, defendido por Freire (2010), refletir sobre a realidade. Essa reflexão precisa ser estimulada, e a literatura pode ajudar nesse aspecto.

A leitura literária no Ensino Médio pode auxiliar na formação humana do estudante. Para contribuir com essa reflexão, trazemos a história do ensino de Literatura nessa fase da escolarização, a fim de refletir sobre os papeis assumidos na escola brasileira. Em seguida, debruçamo-nos sobre o soneto "Sobre estas duras, cavernosas fragas", de Bocage. Com essa análise, pretendemos identificar aspectos que possam contribuir para a formação do aluno a partir da mobilização de recursos históricos, estruturais e temáticos. A leitura e reflexão sobre o poema possibilitaria ao discente refletir e agir por meio da tomada de decisões e do posicionamento crítico frente ao mundo, a si mesmo e ao outro.

O poema objeto de estudo está inserido em antologia de poesias integrante do PNBE 2013. A poesia é um gênero que pouco entra nas práticas escolarizadas. $\mathrm{E}$ a antologia é uma modalidade de livro que contém diversidade de textos do gênero em questão. A obra eleita - Poesia faz pensar, organizado por Carlos Felipe Moisés, é formada por 42 poemas. Entre os poemas do título, elegemos para este artigo o soneto cuja data de produção mais se distancia do leitor contemporâneo. Entendemos que a distância temporal pode ser fator que implica presença de mediação para a obra. Ao analisarmos a poesia, buscamos refletir 
acerca das características históricas do período de publicação e da biografia do autor, a fim de contextualizarmos o texto. Após, discutimos o tema, a estrutura, os recursos estéticos e a relação com a educação do leitor.

\section{Ensino da Literatura no Brasil: DA EDUCAÇÃo JESUítica À ATUALIDAde}

A história do ensino da Literatura traz diversos fatores que interferem até hoje no sistema educativo do país, por isso trouxemos esta reflexão neste artigo. Assim, pontuaremos os diversos momentos do percurso do Ensino Médio no Brasil.

Com a vinda dos jesuítas, que tinham como objetivo a catequização dos índios nativos do país, em 1549, instalou-se o ensino de Literatura. A finalidade da literatura na instrução dos colégios jesuíticos voltados à Religião era "formar catequistas para converter os indígenas, e letrados capazes de fazer belos poemas e sermões" (MALARD, 1985, p. 8). Dessa forma, a literatura era compreendida como subsídio para a educação. Durante a colonização do país, em geral, os senhores de terra não valorizavam a cultura escrita (MALARD, 1985). A vida urbana, que poderia favorecer atividades culturais, não existia nesse tempo. Logo, a literatura não teve apreço nesse período.

No século XVIII, quando os jesuítas foram expulsos do Brasil, foram improvisadas aulas por professores sem instrução, nem gratificação significativas, o que trouxe queda à qualidade do ensino. Com a vinda da Família Real para o Brasil, em 1808, o Ensino Superior foi ampliado, e o Ensino Secundário passou a ser considerado como preparação para ingresso no Ensino Superior (ZINANI; SANTOS, 2012). Contudo, o ensino de literatura mantinha-se distante dos estudantes:

O ensino continuava, portanto, distanciado da realidade, formalista, sem
um contato direto com seu objeto - a própria literatura, o texto completo e
concreto. Literatura concebida como "belas-letras", a arte da palavra bela em
si e para si, cujos autores eram tidos como gênios inspirados, romancistas que
viviam numa torre de marfim, poetas em constante viagem ao mundo da lua
(MALARD, 1985, p. 9)

Com a independência, em 1822, o ensino nos liceus, de inspiração francesa, teve início na escolarização secundária do Brasil. O Colégio Pedro II, no Rio de Janeiro, foi padrão nacional e o maior representante desse ensino. Para Zinani e Santos (2012), no final do Império, o ensino secundário estava um pouco melhor do que em seu início.

A literatura brasileira, conforme Malard (1985), só foi inserida no currículo com a República, em 1889, mais especificamente, com a reforma educacional proposta por Benjamin Constant. A literatura clássica da antiguidade era ensinada por meio de manuais de retórica. O texto era valorizado pela estilística e figuras de linguagem. Os alunos deveriam decorar períodos literários, biografias e listas de obras, algumas vezes acompanhadas de anotações críticas, que não necessitavam de leitura completa. Essa reforma trouxe o pen- 
samento positivista ao ensino, que teve influência dos meios militares. Esse modelo de educação, ainda distante do texto literário, permaneceu até o fim da primeira metade do século XX.

Zinani e Santos (2012) afirmam que a década de 1920 marcou o início de uma nova sociedade, com novos pensamentos políticos, defendidos, inclusive, na Semana da Arte Moderna de 1922. Essa mudança refletiu também na educação. Nesse período, com o fim da Primeira Guerra Mundial, chegaram ao Brasil as ideias da Escola Nova, sugerindo a autonomia do aluno e influenciando a reformulação educacional no país.

Outro marco importante na história, conforme as autoras, foi a criação do Ministério da Educação e da Saúde, em 1930, instalado pelo governo de Getúlio Vargas. Nesse mesmo Governo, ocorreu a Reforma Capanema, em 1941, que priorizou a educação da elite, pois era dividida conforme a função que o estudante tinha na sociedade. Essa reforma trouxe mudanças, principalmente ao ensino secundário, que passou a ser dividido em ciclos ginasial e colegial.

O colegial apresentava-se em duas modalidades: clássico e científico e tinha caráter preparatório para os estudos superiores. O clássico e o científico conviviam com os cursos de cunho profissionalizante que não davam acesso aos graus superiores (ZINANI; SANTOS, 2012, p. 41).

Esse sistema de ensino levou em consideração as necessidades da sociedade no mercado de trabalho daquele momento. Ocorreram poucas modificações no sistema até 1961, quando foi estabelecida a equivalência dos cursos de nível médio pela Lei de Diretrizes e Bases. Segundo Malard (1985), a partir de 1960, as mudanças no ensino trouxeram a análise e interpretação de textos de inspiração francesa. Por exemplo, o poema, por ser curto, era analisado de forma profunda pelos professores, porém era difícil de ser compreendido pelos alunos, que não possuíam leituras o suficiente nem relação íntima com a literatura a ponto de acompanhar as explicações. Dessa forma, a literatura era vista como algo sem utilidade e a monotonia do método de estudo poético não atraía a atenção do estudante. A literatura, nesse contexto, não era percebida como a prática social para autor e leitor:

\footnotetext{
Prática social no sentido de atividade humana em intenção transformadora do mundo, que expressa o peculiar da relação do homem com o mundo, os modos de ser do homem e do mundo. Já não se dá mais crédito ao valor eterno e universal da linguagem literária em si, como produto da genialidade do produtor. A Literatura é uma prática historicizada, influenciada por valores defendidos pela classe que domina a sociedade e pelos da classe que a ela se contrapõe. Existem em determinado tempo e espaço históricos projetados no prosseguir da História. (MALARD, 1985, p. 10-11).
}

A autora ressalta a relevância da literatura na formação para a vida do educando, no sentido de prepará-lo para ser ativo e não oprimido pela sociedade, compreendendo seu valor no mundo. 
A nova Lei de Diretrizes e Bases da Educação Nacional, Lei 9.394/96, reformulou o ensino em todos os níveis e está em vigor atualmente. De acordo com a Lei, o Ensino Médio é a etapa final da Educação Básica, com duração mínima de três anos. Ele também é normatizado pela Constituição da República Federativa do Brasil de 1988 e pelo Plano Nacional de Educação (2014/2024). As finalidades apresentadas para o Ensino Médio são as seguintes:

[...] a consolidação e o aprofundamento dos conhecimentos adquiridos no ensino fundamental, possibilitando o prosseguimento de estudos; a preparação básica para o trabalho e a cidadania do educando, para continuar aprendendo, de modo a ser capaz de se adaptar com flexibilidade a novas condições de ocupação ou aperfeiçoamento posteriores; o aprimoramento do educando como pessoa humana, incluindo a formação ética e o desenvolvimento da autonomia intelectual e do pensamento crítico; a compreensão dos fundamentos científico-tecnológicos dos processos produtivos, relacionando a teoria com a prática, no ensino de cada disciplina (BRASIL, 1996).

Dessa forma, a leitura literária pode auxiliar no desenvolvimento das habilidades citadas por meio das reflexões que ela pode provocar. Durante o Ensino Médio, o aluno deveria desenvolver competências fundamentais para o desempenho da cidadania e para seu autorreconhecimento como produtor de conhecimento. O currículo dessa etapa aborda aspectos que auxiliariam na formação do ser humano em sua vida em sociedade, na atividade produtiva e em suas experiências subjetivas. Vale lembrar que os pilares da educação, conforme a UNESCO, apontam como atribuição da educação: aprender a conhecer, a fazer, a viver e a ser.

Os Parâmetros Curriculares Nacionais, embora dividam o conhecimento em áreas, entendem que ele está inter-relacionado. As áreas, conforme os PCNs, são: Linguagens, Códigos e suas Tecnologias, Ciências da Natureza, Matemática e suas Tecnologias e Ciências Humanas e suas Tecnologias. Assim, é possível promover a interdisciplinaridade na escola, posto que a organização garante base científica e tecnológica, em que teoria e prática de diversas áreas se complementam na solução de problemas. A área de maior interesse desta investigação é a de Linguagens, Códigos e Tecnologias. O Documento define linguagem como:

[...] capacidade humana de articular significados coletivos em sistemas arbitrários de representação, que são compartilhados e que variam de acordo com as necessidades e experiências da vida em sociedade. A principal razão de qualquer ato de linguagem é a produção de sentido (BRASIL, 2000, p. 19).

Por meio da linguagem, o ser humano se comunica em sociedade e organiza seus pensamentos. Pela linguagem, também se manifesta a literatura. Os PCNs sinalizam que essa modalidade de escrita não necessita ser estudada somente pela historicidade, mas integrada ao momento da disciplina de Língua Portuguesa, em que a leitura é trabalhada. Ainda no Documento, percebemos que as competências e habilidades a serem desenvolvidas no en- 
sino de Língua Portuguesa ocorrem por meio da investigação e da compreensão. Os PCNs tratam a literatura como um legado cultural, que deve ser conhecido e preservado pela nação. Logo, os aspectos históricos estão presentes, no entanto, não é dada ênfase à leitura literária e ao potencial de formação humana que essa prática pode trazer, inclusive para o cumprimento das finalidades do Ensino Médio, citadas anteriormente. Podemos inferir, portanto, que o ensino da literatura seria uma prática formativa, que valoriza o homem e o seu potencial de humanização, apesar do papel reduzido que a legislação concede à literatura no Ensino Médio.

O Ministério da Educação (2017) está reestruturando o sistema do Ensino Médio, e a proposta anunciada prevê uma Base Nacional Curricular Comum. Essa Base norteará os currículos das escolas, tornando as disciplinas de Língua Portuguesa e Matemática obrigatórias nos três anos. Cada Estado da nação e o Distrito Federal organizarão seus currículos tendo como referência a Base Nacional Curricular Comum e as demandas dos alunos como elementos norteadores, orientadas a partir de diretrizes estabelecidas pelos conselhos estaduais de educação. A Literatura, assim, integra o ensino de Língua Portuguesa.

Este breve histórico aponta mudanças no ensino da literatura e sugere reflexões sobre a importância dessa disciplina em sala de aula, uma vez que reconhecemos seu potencial, apesar de a legislação reduzir sua importância.

\section{OS SENTIDOS DO POEMA EM EVIDÊNCIA}

Entre os textos literários presentes na sociedade, a poesia deveria estar no cotidiano da Educação Básica, incluindo o Ensino Médio.

A definição de "poesia" altera-se de acordo com o momento histórico e a cultura de cada povo. A Grécia Antiga foi o local de origem desse gênero literário, quando toda a literatura era chamada de poesia. Conforme Zilberman e Silva (1990), o texto poético tinha como finalidade a educação do homem, pois, por meio das tragédias gregas, eram passadas as histórias, os valores, a religião e a cultura do povo. Os torneios públicos difundiram as tragédias e permitiram que textos como Ilíada e Odisseia fossem conservados. Com o passar do tempo, foram surgindo novos gêneros a partir da poesia, ampliando o conceito de literatura.

O poema possui natureza histórica e paradoxal, postula Paz (1982), pois por um lado são datáveis e, por outro, anteriores a qualquer tempo. As obras Odisseia e Ilíada, por exemplo, não existiriam sem a história grega, e sem elas, a realidade da Grécia poderia ser diferente.

O poema é um tecido de palavras perfeitamente datáveis a um ato anterior a todas as datas: o ato original com que principia toda a história social ou individual; expressão de uma sociedade e simultaneamente fundamento dessa sociedade, condição de sua existência (PAZ, 1982, p. 226).

O poema, portanto, é produto social e também condição prévia à existência da sociedade, pois, além de refletir acerca da realidade, registra e favorece a interação com outras gerações. 
Conscientes disso, analisaremos o poema, a partir de estudos de Paz (1982) e de Candido (2008), que faz exercício de análise de seis poemas, observando que cada "um requer tratamento adequado à sua natureza" (p. 6). Serão respeitadas as peculiaridades da poesia, contudo, tentaremos priorizar tópicos como contexto de produção do texto (tempo histórico), aspectos estruturais e estilísticos, e ainda, aproximação com a realidade, momento em que se busca evidenciar possibilidade de humanização inerente aos poemas.

A obra Poesia faz pensar, publicada em 2011, pela editora Ática, foi organizada por Carlos Felipe Moisés. O livro é formado por poesias produzidas em quatro séculos, ou seja, os autores viveram em diferentes épocas e locais, com diferentes contextos históricos, sociais e culturais. Essa variedade permite ao leitor perceber a evolução do texto poético, bem como, relacionar criticamente o contexto histórico, as características das escolas literárias e os assuntos que permeiam cada poema. Além disso, possibilita a percepção das diversas formas dos poetas expressarem-se por meio da poesia. Essa possibilidade de reflexão crítica pode auxiliar o aluno a repensar a sua realidade social, sentimentos e opiniões, contribuindo para a formação e ação no mundo.

A antologia é organizada em cinco blocos temáticos formado por poesias brasileiras e portuguesas, assim denominados: É tudo quanto sinto um desconcerto (oito poemas), Um contentamento descontente (nove poemas), Errei todo o discurso de meus anos (nove poemas), Continuamente vemos novidades (oito poemas), Se lá no assento etéreo, onde subiste (oito poemas). Cada bloco é seguido de um tópico denominado comentários, no qual o organizador articula os textos do tópico. Para organizar a coletânea, Moisés (2011) afirma que partiu do princípio de que a poesia, além de sentir, também nos faz pensar. $O$ processo de pensar inicia no momento em que o autor decide o que e como escrever ao seu leitor. Assim, sentir e pensar são atividades que podem andar juntas nos textos literários, especialmente de poesias, como argumenta o autor:

\footnotetext{
A presente antologia foi concebida com o propósito de valorizar a poesia, que, além de levar a sentir, também faz pensar, ou seja, a poesia encarada como forma de conhecimento, como uma das mais poderosas ferramentas de indagação oferecidas ao ser humano, no encalço de compreender o mundo, mesmo sabendo das limitações da tarefa.

Os poemas aqui reunidos, em sua variedade de temas e autores, épocas e estilos, nos ensinam que o bicho homem é, na sua essência, contraditório. É que a cada um de nós se aplica o que afirma o mesmo Fernando Pessoa, esse que talvez seja o maior poeta-filósofo da nossa língua: “O que em mim sente 'stá pensando”. Razão pela qual poesia, poesia para valer, sempre dá o que pensar, embora isso não deva induzir ninguém a deixar de sentir (MOISÉS, 2011, p. 11, 12).
}

Para iniciar o estudo de um texto, é importante conhecer um pouco seu enunciador. Bocage, poeta nascido em Portugal, em 1765, é o autor da poesia em análise. Ao tecer breve biografia, Moisés (2011) destaca que o poeta participou da associação literária Nova Arcádia, mesmo não seguindo o formalismo do grupo. O escritor português teve vida irregular e manifestava temperamento rebelde, amores infelizes e infortúnios. Ficou conhecido 
por suas sátiras, que ridicularizavam as autoridades de Lisboa. Também escreveu extensa obra e suas poesias dividem-se entre líricas e satíricas. Foi precursor do Romantismo e morreu, em 1805, em Lisboa. Atualmente, ousamos dizer que se trata de um quase desconhecido entre os estudantes do final da Educação Básica brasileira. Motivo a mais para o poema em questão ser trazido a discussão. Afinal, o que teria a nos dizer um poema escrito por um português que viveu na segunda metade do século XVIII e primeiros anos do XIX? Vamos ao poema:

\author{
[Sobre estas duras, cavernosas fragas] \\ Sobre estas duras, cavernosas fragas, \\ Que o marinho furor vai carcomendo, \\ Me estão negras paixões na alma fervendo \\ Como fervem no pego as crespas vagas. \\ Razão feroz, o coração me indagas \\ De meus erros a sombra esclarecendo, \\ E vás nele (ai de mim!) palpando, e vendo \\ De agudas ânsias venenosas chagas.
}

Cego a meus males, surdo a teu reclamo, Mil objetos de horror com a ideia eu corro, Solto gemidos, lágrimas derramo.

Razão, de que me serve o teu socorro? Mandas-me não amar, eu ardo, eu amo;

Dizes-me que sossegue, eu peno, eu morro. (BOCAGE, 2011, p. 16)

Um poema tem natureza histórica, conforme indicou Paz (1982). A localização temporal do texto pode revelar decisões de estilo e de temas escolhidos pelos escritores, além de relatar fatos e costumes de certo tempo. Sabendo da relevância da análise histórica, apontaremos, aqui, características do período literário em que a poesia foi publicada.

De acordo com Bosi (2006), o Arcadismo trazia como características a imitação da natureza, dos clássicos e a ausência de subjetividade. Assim, a linguagem seguia o pensamento racional, claro e regular. As poesias apresentavam cenários acolhedores e naturais, como o campo e os pastores, que representavam a aversão à pompa e à sofisticação das cortes europeias. Os poetas sugeriam, por meio das poesias, que a cidade era um ambiente livre de espontaneidade, e o campo era a única forma de libertar-se das normas sociais de etiqueta.

Este soneto não possui título. Por esse motivo, Moisés (2011) explica, em nota de rodapé, que optou por utilizar o primeiro verso repetido entre colchetes em todos os poemas com essa peculiaridade no livro. A forma e o título são elementos que participam da composição de um texto, auxiliando também nas possibilidades de concretização de sentindo.

O poema em análise é um soneto, forma clássica: composto de duas quadras e dois tercetos, em sua forma tradicional, possui versos decassílabos com rimas abba/abba/cde/cde. 
Todos os versos são compostos por dez sílabas poéticas, com exceção do último, que possui doze. Quanto às rimas, elas não seguem a versão tradicional, pois possuem esquema abba/ abba/cdc/dcd. As últimas palavras de cada verso são substantivos ou verbos. Destacamos a presença de verbos no gerúndio no primeiro e segundo quartetos: carcomendo, fervendo, esclarecendo, vendo, que sugerem ritmo contínuo no poema. O ritmo, como condição do poema, conforme Paz (1982), também transmite essa sensação de nervoso, confusão.

O autor vale-se da adjetivação: "duras", "cavernosas", "marinho", "negras", "crespas", "feroz", "agudas", "venenosas", "cego", "surdo", que conferem maior caracterização aos sentimentos que demonstram sofrimento expressos no poema.

$\mathrm{Na}$ primeira estrofe, o eu-poético está sobre as rochas observando o mar e comparando as ondas agitadas com suas paixões, que são caracterizadas pela cor negra. "Negras" sugere a ideia de algo pesado, depressivo ou até mesmo proibido, errado perante a sociedade ou a consciência do eu-poético. Dessa forma, ele indica que as paixões, assim, como as ondas, fervem em sua alma, deixam-no agitado, nervoso como o mar, ou ainda apontam a dificuldade de controlar as paixões, assim como não dominamos as ondas, apenas precisamos aprender a lidar com a força que emanam. Podemos dizer que, na quadra em questão, há a confissão do estado emocional do sujeito.

Como recurso estilístico que oportuniza a percepção estética do poema, o eu-lírico utiliza a metáfora no verso três ao dizer que as paixões fervem na alma. A comparação é utilizada no verso quatro, ao relacionar essas paixões que fervem na alma com as ondas que fervem no mar.

$\mathrm{Na}$ segunda quadra, a razão questiona o coração sobre os erros do eu lírico, sugerindo que a razão clareia a sombra de seus erros, deixando-os evidentes no coração do poeta. Assim, a razão segue explorando o coração de forma dolorosa, causando dor e sofrimento. A personificação da razão é elemento presente no poema, conferindo interação entre ela e o eu poético.

No verso 5, ocorre uma apóstrofe, quando o eu poético interpela a razão personificada. A sinestesia mostra-se no verso 7, pela afirmação de que a razão apalpa e vê seu coração; essas figuras de linguagem indicam conversa entre a razão e o sujeito. Uma interjeição exclamativa "ai de mim!" também é utilizada neste verso, demonstrando que o eu poético sente-se vítima da situação frente à luta entre razão e amor. O sujeito lírico se vale de metáforas no verso 8 , ao mencionar que suas chagas são venenosas, dando intensidade ao sentido de chagas.

No primeiro terceto, o poeta afirma tentar esquecer seus erros, pois lhe causam horror, fazendo-o gemer e chorar. No verso 9 , percebemos a presença da sinestesia quando o sujeito afirma estar "Cego a meus males, surdo a teu reclamo". Também encontramos a hipérbole no exagero de "mil objetos de horror", dando ênfase ao sofrimento. No último verso da estrofe, percebemos a gradação de gemidos e lágrimas, novamente remetendo ao sofrimento vivenciado pelo eu lírico.

Nos três últimos versos, o eu lírico faz uma pergunta retórica à razão sobre o proveito do socorro que ela oferece a ele, uma vez que não consegue segui-los, amando quando 
não deve, e sofrendo quando deve acalmar-se. No verso 13, temos uma metáfora quando o sujeito afirma arder. Encontramos um paradoxo nos versos 13 e 14 entre amar e não amar, sossegar e penar, morrer. Nesses versos, também percebemos hipérboles, expressa principalmente pelo "morrer". Essa figura de linguagem dialoga com o modo como o jovem se expressa e favorece a identificação de estudantes com o poema. Essas figuras indicam a intensidade do sofrimento que está sendo demonstrado.

O uso das rimas e das sílabas poéticas anuncia um ritmo intencional ao poema. Percebemos, então, outro elemento estético com o objetivo de aguçar nossa sensibilidade e auxiliar na compreensão do poema. A estrutura do poema, as rimas e a temática sinalizam a identidade do eu lírico no momento da escrita da poesia. Essa foi a forma como o poeta conseguiu dizer a sua palavra artisticamente.

Após a exposição de todos os poemas, Moisés (2011) tece comentários sobre as poesias. O poema em análise pertence ao primeiro grupo temático da antologia "é tudo quanto sinto um desconcerto", que reúne textos sobre o tema desconcerto:

\footnotetext{
"Desconcerto" quer dizer desordem, desarmonia, desencontro, confusão. Ao empreender sua meditação, o poeta se revela um estranho para si mesmo, um ser dividido, à mercê de impulsos que ele não é capaz de controlar (Pausa. Não é um pouco assim com todos nós?) (MOISÉS, 2011, p. 24-25).
}

Desconcerto pressupõe o contraste entre o estado de espírito ideal, pacífico, sereno e harmonioso consigo e com o mundo, e os fatos cotidianos inesperados, causadores de tumulto, que provocam emoções arrebatadoras, instintivas ou sentimentos como o amor. No poema que estamos analisando, a temática do desconcerto aparece sob a forma do conflito entre a razão e o coração e as emoções sofridas pelo eu lírico ao se confrontar com essa situação. Inicialmente, o poeta expõe elementos da natureza como as fragas, o pego e as vagas, em linguagem atual, os rochedos, o mar e as ondas agitadas que, em seguida, utilizará para comparações com os seus sentimentos.

Ao entrar em contato com a poesia, por meio da reflexão, o leitor pode identificar-se com o desconcerto relatado pelo poeta, e, ao mesmo tempo, compreender e ter empatia frente a esses conflitos como parte da vida humana, inerente à complexidade do ser. Nesse movimento de formar-se enquanto ser humano, o leitor pode refletir e dar-se conta de qual é o seu papel na sociedade, assim como agir para intervir positivamente na construção individual e social.

O poema mostra o homem conflitante com sua razão e suas atitudes: "Mandas-me não amar, eu ardo, eu amo;/Dizes-me que sossegue, eu peno, eu morro". A imagem que temos do que é correto ou não fazer vem da nossa cultura, da vivência com o outro, conforme Freire $(2000,1987)$. Dessa forma, os sentimentos relatados pelo eu lírico, ao longo do texto, são um retrato das suas experiências.

O sujeito poético estabelece relação com sua própria razão e o coração durante o poema, demonstrando conhecimento de si, fato que, conforme citamos no referencial teórico deste trabalho, contribui para a formação do ser humano. De acordo com Freire (2000), 
durante a vida aprendemos diariamente por meio das relações que estabelecemos. Assim, o leitor, ao interagir com o poema, refletir sobre sua razão e seu coração, como reflete o eu lírico, além de conhecer mais sobre os sentimentos humanos, também pode desenvolver o conhecimento próprio e o pensamento crítico sobre suas atitudes, o que Freire (2010) indica ser um caminho para a autonomia.

\section{CONSIDERaÇões Finais}

O objetivo inicial deste trabalho foi identificar aspectos que possam contribuir para a emancipação do aluno a partir da mobilização dos recursos históricos, estruturais e temáticos presentes num poema do poeta português Bocage. Considerando o fato de termos analisado apenas uma poesia, salientamos que os resultados indicam apenas uma amostra das possibilidades do gênero na vida do estudante.

Nesse sentido, no poema em questão, o eu lírico reflete sobre suas escolhas de vida, marcada por infortúnios e desilusões, além de nos revelar uma visão de mundo comum aos escritores do Arcadismo e Romantismo. O soneto emprega estrutura clássica que pode favorecer a organização mental ao leitor, facilitando sua leitura e interpretação. Também percebemos essa característica pela presença de elementos da natureza, que facilitam as relações com o conhecimento prévio do leitor.

O texto aponta o conflito penoso entre razão e emoção. O momento da escolha na tomada de decisões diárias presente na vida de todos os seres humanos e que, muitas vezes, pode trazer sofrimento devido à angústia da dúvida, como eu lírico expressou. Ao entrar em contato com a poesia, portanto, o aluno não só tem uma experiência estética, mas também a oportunidade de conhecer sobre a história do mundo e de se colocar no lugar do outro, vindo a compreender melhor suas próprias emoções.

Para que esses aspectos possam ser realmente percebidos pelo leitor, a poesia pode ser trabalhada por meio de estratégias de letramento literário. Percebemos que através do tempo, a literatura foi vista pela escola de formas diferentes e pela experiência que temos em educação, sabemos que muitas vezes ela foi utilizada apenas como pretexto para o ensino de gramática. O estudo do poema sinaliza o potencial da poesia para a formação do aluno, mas, para isso, precisa ser respeitada a natureza do texto artísticos, cuja polissemia lhe é intrínseca.

\section{REFERÊNCIAS}

BOSI, Alfredo. História concisa da literatura brasileira. São Paulo: Cultrix, 2006.

BOCAGE. [Sobre estas duras, cavernosas fragas]. In: MOISÉS, Carlos Felipe (Org.). Poesia faz pensar. São Paulo: Ática, 2011. 
BRASIL. Lei de Diretrizes e Bases da Educação Nacional: no 9394/96. Brasília, 1996.

BRASIL. Parâmetros Curriculares Nacionais (PCN's). Ensino Médio Parte II - Linguagens, Códigos e suas Tecnologias. Brasília: MEC/SEF, 2000.

CÂNDIDO, Antônio. O direito à literatura. In Vários escritos. São Paulo: Duas Cidades, 2011.

Na sala de aula: caderno de análise literária. 8. ed. São Paulo: Ática, 2008.

FREIRE, Paulo. Educação como prática da liberdade. São Paulo: Paz e Terra, 2000.

. Pedagogia da autonomia: saberes necessários à prática educativa. São Paulo: Paz e Terra, 2010.

. Pedagogia do oprimido. São Paulo: Paz e Terra, 1987.

LAJOLO, Marisa. Do mundo da leitura para a leitura do mundo. São Paulo: Ática, 2000 .

MALARD, Leticia. Ensino e literatura no $\mathbf{2}^{\mathbf{0}}$ grau: problemas \& perspectivas. Porto Alegre: Mercado Aberto, 1985.

MINISTÉRIO DA EDUCAÇÃO. Novo Ensino Médio - Dúvidas. < http://portal.mec.gov. $\mathrm{br} /$ component/content/article?id=40361\#nem_01>

Acesso em 20/07/2017, $18 \mathrm{~h}$.

MOISÉS, Carlos Felipe (Org.). Poesia faz pensar. São Paulo: Ática, 2011.

PAZ, Octavio. O arco e a lira. Rio de Janeiro: Nova Fronteira, 1982.

ZILBERMAN, Regina; SILVA, Ezequiel Theodoro. Literatura e pedagogia: ponto e contraponto. Porto Alegre: Mercado Aberto, 1990.

ZINANI, Cecil Jeanine Albert; SANTOS, Salete Rosa Pezzi dos. Ensino da literatura: pressupostos teóricos. In: ZINANI, Cecil Jeanine Albert et al. Transformando o ensino de língua e literatura: análise da realidade e propostas metodológicas. Caxias do Sul: EDUCS, 2012. 


\section{DAdOS DOS AUTORES}

\section{Rosana Andres Dalenogare}

Mestre em Educação pela Universidade de Caxias do Sul (UCS). Caxias do Sul/RS- Brasil. Professora de Língua Inglesa e Língua Portuguesa. randresd@gmail.com

\section{Flávia Brocchetto Ramos}

Doutora em Linguística e Letras pela PUCRS. Coordenadora do Programa de Pós-Graduação em Educação - Mestrado e Doutorado da Universidade de Caxias do Sul (UCS). Caxias do Sul/RS-Brasil.fbramos@ucs.br

\section{José Edimar de Souza}

Doutor em Educação pela Unisinos. Professor do Programa de Pós-Graduação em Educação - Mestrado e Doutorado da Universidade de Caxias do Sul (UCS). Caxias dos Sul/ RS-Brasil.Jesouza1@ucs.br

Submetido em: 31-5-2018

Aceito em:25-3-2019 